\title{
"The air of impossibility has been removed": Realist Political Drama(dy) and the Trope of Becoming President
}

\section{Antje Dallmann}

Humboldt-Universität zu Berlin

\begin{abstract}
Over the past ten to fifteen years, film and TV culture have offered new and more complex negotiations of presidential politics through depictions of fictional American presidents. While in the past American popular culture celebrated the president as overwhelmingly positive, larger-than-life figure, recent representations have introduced more complex characters who face, or even trigger, complicated and morally ambiguous conflicts. This article investigates how The West Wing, House of Cards and Veep, three political TV shows, make use of the emerging trope of a brokered nomination convention in order to question one-dimensional fictional representations of the American president and presidential politics.
\end{abstract}

Keywords: popular culture, presidential drama(dy), political tv shows, political fiction

The atmospheric opening credits of the web TV series The Politician start with a view on an empty wooden typecase. Its compartments are successively being filled with an assortment of strikingly unrelated items: a Harvard badge, a debate team sticker, a silver spoon, a handful of multicolored pills, to name a few (2:41-4:00). ${ }^{1}$ Books are added, including four apparently much-thumbed green cloth-bound volumes with the names of recent 
US-presidents from Ronald Reagan to Barack Obama on their spines, together with a fifth book - still in its untouched white jacket - entitled The Idiot's Guide to Clowning. Badges from Nixon's, Kennedy's, and Reagan's presidential campaigns are on display. Next to them, three silver cartridges are stored. We discern an ancient-looking wooden gadget that prints out one-word hashtags on a narrow roll of paper and begin to realize that the typecase is built in the form of a human body, the upper part of whose head is filled with a replica of the White House. The typecase, this male body carved out of bright wood, is being erected - a puppet on strings -, is covered with a translucent layer of a wax-like material and dressed in a bespoke suit, a US-American flag pin placed carefully on the right lapel. Then, its hand comes to life and, at last, we see the body raising its head, looking straight into the camera, at us.

The Politician, a Netflix production created by Brad Falchuk, Ryan Murphy and Ian Brennan, came out in the fall of 2019, with the presidential election year 2020 just around the corner. The show's narrative revolves around Payton Hobart, introduced as mechanical man made of wood on the surface and of trivia within. Payton - a white, entitled Santa Barbaran high school student - apparently has a dream. "It was a waking dream," he explains in his Harvard intake interview with which the first episode starts, "the kind that arrives in the twilight between sleep and real world. I [...] said out loud: 'I'm going to be President of the United States." The Harvard dean who conducts the interview is not surprised: "It does seem to be the hot job everyone aspires to nowadays. The air of impossibility has been removed" (1:00-1:01). In the show's universe of absurdly accomplished and abundantly moneyed high school students who are equally well-versed in Mandarin as in empirical sociology, to become president of the United States is in fact an achievable mission. And Payton is not just everyone. $\mathrm{He}$ has carefully examined the strategies that lead to political success and is prepared to tick all the boxes on his way to the White House, starting with a campaign for student body president. He has no firm political beliefs, no pre-set agenda, no party affiliation, and he is prepared to use all means necessary on the path to his goal, the US presidency, which he pictures as a continuous event in showmanship and image cultivation punctuated by media-effective campaigns for office.

At first, The Politician may come across as yet another high school dramady. With Payton and his teenage team of media-savvy campaign staffers, the show meanwhile also offers an allegorical reading of the mechanics of 
professionalized politics in a post-truth, post-real era in which to become president is an achievable goal - provided the candidate is rich, white, and male. Payton is depicted as a cross between privileged adolescent nerd with all the gifts and privileges that economic and cultural capital can afford and - quite simply - an automaton. Yet while he might already be corrupted by his will to public success, he is not remotely controlled by a hidden power. If anything, he is a puppet that is brought to life by the very same social media machinery with its broadly proliferated opinions and values that he also uses for his own campaigning ends. Openly troubled by what he feels is a lack of emotion and empathy, by an absence of a "real me," Payton holds back nothing. In a post-modernist vein, thus, he is exactly what he pretends to be, on the surface and underneath.

Combining the established roles of candidate and incumbent, the promise of youthful innocence and enthusiasm with callousness and a political professionalism that borders on the ridiculous, The Politician invokes, revises and subverts long-standing tropes of political fiction. It evokes, but also revises the narrative of political corruption, which in contemporary culture is increasingly linked to the use of social media as manipulative campaigning tools. As a somewhat genre-bending, satirical show, The Politician may at the same time also be read as a critical re-negotiation of realist political fiction. ${ }^{2}$ Similarly to American Horror Story's seventh season "Cult," which was also created by Murphy and Falchuk, The Politician provides the story of a young man's rise to political power within a less real than surreal narrative world that, nevertheless, strangely reverberates contemporary cultural and political sensibilities. The Good Fight, another recent show, likewise presents real-life politics through increasingly bizarre and unreal TV images perceived by the well-informed, outraged and politically involved liberal lawyer Diane Lockhart (Christine Baranski). "Truth only takes you that far, and then you need lies," she sarcastically states. ${ }^{3}$

2 See The West Wing, created and dir. Aaron Sorkin, with Rob Lowe, Allison Janney, Richard Schiff, John Spencer, and Martin Sheen, NBC (1999-2006); Designated Survivor, created David Guggenheim, with Kiefer Sutherland and Natasha McElhone, ABC/Netflix (2016-2019); Graves, created Joshua Michael Stern, with Nick Nolte and Sela Ward, Epix (2016-2017); House of Cards, created Beau Willimon, based on $\mathrm{HoC}$ by Michael Dobbs (book) and Andrew Davies (original series), with Kevin Spacey and Robin Wright, Netflix (2013-2019); Veep, created Armando Iannucci, with Julia Louis-Dreyfus, HBO (20122019).

3 “Day 450," dir. Frederick E.O. Toye, season 2, The Good Fight (15 Apr. 2018). 
The Good Fight, as well as The Good Wife (2009-2016) and the political satire BrainDead (2016) with its science-fiction and post-apocalyptic elements, all three created by Michelle and Robert King, dissect the impact on politics of a prevalent culture of misinformation and lies. All these shows also examine how the modes of operation of this culture can be revealed by means of fictional narratives that go beyond realist conventions of storytelling, offering insight into ongoing political drama, both real and imagined.

Yet more traditional, realist political fiction also deserves close attention. The Politician, as presidential dramady, comments on the growing number of political TV shows that are narrated in a realist mode and that came out from the early 2000s onwards, influenced by Aaron Sorkin's groundbreaking The West Wing (TWW, 1999-2006): from Veep (2012-2019), to House of Cards (HoC, 2013-2019), Graves (2016-2017) to Designated Survivor (2016-2019). In their attempt to mirror political events while also offering continuous narrative closure, they structurally align with a type of thinking that, when applied to the interpretation of real-life politics, could be analyzed following Richard J. Hofstadter's famous concept of the "paranoid style." ${ }^{4}$ In the following, I discuss the cultural work of the TV genre of presidential drama(dy) as realist political fiction. I focus on political image cultivation, campaigning, and the process of running for office, topics that dominate political fiction, which often underrepresents day-to-day political practice with its necessary focus on actual political concerns. I argue that "real" places, which give local color to realist political narratives, also function as symbolical spaces - as "chronotopes" in Mikhail Bakhtin's sense ${ }^{5}-$ that imbue political fictions with particular symbolical meanings and allow for interpretations that may align them with tropes of conspiracy thinking.

Genre will be understood, following Jason Mittell, ${ }^{6}$ as a cultural category, shifting "the site of genre analysis [...] from isolated texts recategorized by their genre to culturally circulating generic practices that categorize texts" (13). Recent political fiction in general and presidential drama(dy) in particular are inextricably linked to contemporary US-American cultural and (real-) political landscape in which traditional political camps are irreconcilably opposed, the sitting president is impeached by the House of Representatives while the American electorate is confronted, on a daily ba-

4 “The Paranoid Style in American Politics," Harper's Magazine (Nov. 1964), online (20 Dec. 2019).

5 "Forms of Time and of the Chronotope in the Novel," The Dialogic Imagination: Four Essays: 84-258.

6 Genre and Television: From Cop Shows to Cartoons in American Culture (London: Routledge, 2004). 
sis, with unprecedented truths and lies that, in a world of ubiquitous (social) media coverage, are increasingly difficult to keep apart. The vocabulary that realist presidential drama(dy) devises, uses and converts for the depiction of its characters and the representation of its understanding of political culture will be traced in the following. ${ }^{7}$

\section{Popular Politics/Populist Politics}

A hostility toward political action exists as part of a US-American "national character," Charles Lindholm and John A. Hall argue. While this tendency was already detected by Alexis de Tocqueville, it also informs $\mathrm{Mr}$. Smith Goes to Washington (1939) - Frank Capra's populist classic of political fiction, which is still considered a role-model for US-American film and which continues to shape mainstream American visual culture. ${ }^{8}$ To this day, a fearful suspicion of professional politicians characterizes American culture that comprises populist anti-intellectual, anti-professional, and anti-elitist sensibilities that, according to Beverly Merrill Kelley, have "appeared as a recurring political impetus [...]. Nothing musters American passions, left and right, more swiftly than a sense that elitists [...] are conniving against the common folk" (11). ${ }^{9}$

The idea of an allegedly all-encompassing American "national character," Lindholm and Hall point out, is problematic. It not only creates the illusion of a homogenous national experience, but establishes a coherent "us" against the backdrop of different illegitimate "others" that seek to undermine national unity. The array of anxieties that are linked to the idea of a threatened national "us" comprises the loss of individual agency within republican citizenship that, despite of the concept's populist underpinnings, often takes the form of a fear of the uneducated citizen as political and social other. The field of politics, in this hegemonic discourse, is represented as corrupted, nefarious machine that can only be controlled and fixed by

7 Presidential drama(dy) as evolving cultural category enjoys increasing popularity, which is demonstrated by the immediate impact of Netflix as a streaming service, as it was related to the success of $\mathrm{HoC}$, one of the platform's first original productions; see Dino Grandoni, "With House of Cards Netflix Begins the Future of TV" The Huffington Post (1 Feb. 2013). Netflix has by now introduced "political series" as a search category to allow for easy content findability.

8 "Frank Capra Meets John Doe: Anti-Politics in American National Identity," Cinema and Nation, ed. Mette Hjort and Scott MacKenzie (London: Routledge, 2000): 29-40; Mr. Smith Goes to Washington, dir. Frank Capra, with Jean Arthur and James Stewart, Columbia Pictures (1939).

9 Reelpolitik Ideologies in American Political Film (Lanham, MD: Lexington Books, 2012). 
an innocent outsider, like Capra's boy-rangers leader and everyman John Smith, while career politicians are represented as coopted and manipulated, as characters who are controlled by hidden powers. Significantly, these invisible powers are only rarely identified as US-America's educational and moneyed elite, but are surprisingly (or unsurprisingly?) often represented as women. Political corruption undoubtedly exists. Yet traditional realist political fiction rarely goes beyond giving a simplifying equation between politics and corruption, manipulation, and self-service. Thus, one "meaning" of realist political fiction is a white male fear of the - raced and particularly of the gendered - other as factor within political decision-making. ${ }^{10}$

In contrast to the fear of politics in this populist narrative, American civil religion, famously described by Robert N. Bellah, posits a quasi-religious faith in national political symbols. ${ }^{11}$ Within the nationalist discourse, symbols and practices serve as shorthand for an alleged national unity and as reminders of a common creed that ostensibly unites the American nation. The office of the president of the United States and the actual president as the embodiment of this office are established signs within the language of civil religiosity. The cultural figure of the president as (action-)hero, in this sense, expresses a belief in the endurance of male, mostly white power.

The president as popular cultural icon is thus interpreted within two diametrically opposed narratives: On the one hand, as a career politician who runs for office, the president is a corrupt imposter, manipulator, and potentially a remotely controlled puppet. On the other hand, as incarnation of the office itself and as a father of a nation symbolically pictured as a family, the president is imagined as a stellar figure beyond possible reproach. ${ }^{12}$

In a similar vein, Heather Richardson Hayton points out that the American president is traditionally narrated according to two representational patterns, using the metaphor of the king's two bodies (65). ${ }^{13}$ But this symboli-

10 I have discussed the cultural meaning of the trope of "momism" in American political fiction in "News from the War Room: The Campaign Plot in American TV and Film," Electoral Cultures: American Democracy and Choice, ed. Georgiana Banita and Sascha Pöhlmann (Heidelberg: Winter, 2015): 385-409.

11 "Civil Religion in America" Deadalus 96.1 (1967): 1-21.

12 I use the male form here because the character of the president in political fiction is traditionally male (and white). Exceptions exist, as will be shown in the following, but the character of the "female president" is charged with symbolical meanings that differ noticeably from the normative male model.

13 "The King's Two Bodies: Identity and Office in Sorkin's West Wing," The West Wing: The American Presidency as Television Drama, ed. Peter C. Rollins and John E. Connor (Syracuse, NY: Syracuse UP, 2003): 63-82. 
cal negotiation, Hayton continues, is subverted in Sorkin's The West Wing. The character of President Josiah "Jed" Bartlett - Democrat, Nobel laureate in Economics, former Governor of New Hampshire, three-time member of the House of Representatives, and descendant of a (factual) signatory of the Declaration of Independence - constitutes an example of "presidential iconoclasm," since this "president refuses to serve solely the office or let the office serve solely himself, instead trying to merge both conceptions into one forceful image" (74). $T W W$ - first aired at the onset of the "quality TV" trend in the late 1990s - demonstrates the potential of the TV serial to depict complex political narratives within the long story arcs it allows for. Patrick Finn's characterization of this show as "ideological state apparatus[...] that glamourize[s] repressive state apparatuses" $(114)^{14}$ therefore falls short of acknowledging the more complex negotiations of professional politics in and the heteroglossic meanings of this popular cultural text, reiterating a one-dimensional pattern of interpretation of political fiction. ${ }^{15}$

The complex representation of a progressive, but also ambivalent presidency on $T W W$ has contributed to the evolution of presidential drama(dy) as a cultural category. I will now discuss how $T W W$ as model text is subverted and transformed in later realist political fictions, and my focus will be on how presidential drama(dy) makes use of symbolically charged spaces to (re-)interpret the character of presidential politics.

\section{Chronotopes of Political Fiction}

Political fiction can be understood as negotiation of the conditions of political meaning-making, which - due to its complexity - rarely fits into only one singular interpretative pattern. Its narrative illusion of simply depicting the observed world and its the claim for its authenticity are achieved through a use of realist conventions of storytelling, conventionalized plot structures, and through spatialization. This reference to specific places and particularly to the cityscape of Washington, D.C., however, not only establishes a realist sense of place, but also evokes a powerful US-American political imaginary. ${ }^{16}$

14 "The West Wing's Textual President: American Constitutional Stability and the New Public Intellectual in the Age of Information," The West Wing: The American Presidency as Television Drama, ed. Peter C. Rollins and John E. Connor (Syracuse, NY: Syracuse UP, 2003): 101-24.

15 See Bakhtin for the concept of heteroglossia: The Dialogic Imagination: Four Essays, ed. Michael Holquist, trans. Caryl Emerson and Michael Holquist (Austin: U of Texas P, 1981).

16 See, for instance, Albert Boime for the significance of political memory places: The Unveiling of the Na- 
Presidential drama(dy) references capital sights and other symbolically-charged places effectively. ${ }^{17}$ Iconic spaces like the Capitol, the Lincoln Memorial, the White House Situation Room, the Oval Office, presidential libraries as well as generic White House corridors and D.C. streets are recurring locations within political fiction. They are simultaneously "real" and "imagined" and thus charged with several layers of meaning. For their description, I adopt Bakhtin's concept of the chronotope as narrative means through which "spatial and temporal indicators are fused into one carefully thought-out, concrete whole" (84). In the following, the brokered national Presidential-nominating Convention will be discussed as such a chronotope of political fiction that brings to the fore and accentuates the tension between the conflicting narratives of presidential drama(dy) and indicates the particular emphasis, in realist political fiction, on political orchestration and manipulation.

\section{"May the best man win": Revisiting the Brokered Convention}

The Presidential-nominating Convention was introduced in 1831 as a means of transforming the presidential nomination and election into a more transparent and democratic process. With only one exception, all major party nominees for president were from then on selected at nominating conventions. ${ }^{18}$ As an effort to wrest away power from brokering behind closed doors in proverbial "smoke-filled back rooms" at these conventions, the first primary was in turn held in Florida in 1901.

In the absence of a presidential nominee who emerges from his or her party's primaries as single remaining candidate or as undisputed frontrunner, the danger of a contested convention always looms in which no candidate receives the majority of the delegates' votes in the first ballot. In contested conventions' second and consecutive ballots, delegates become unbound and their votes may be traded for political concessions, a pro-

tional Icons: A Plea for Patriotic Iconoclasm in a Nationalist Era (Cambridge: Cambridge UP, 1998): 11.

17 For $T W W$, the significance of White House spaces has been examined, for instance, by Hayton and by Sebastian Herrmann, "Vor dem Post-Faktischen? The West Wing und die postmoderne "epistemische Verunsicherung" in der Politik," Von Game of Thrones bis House of Cards: Politische Perspektiven in Fernsehserien, ed. Anja Besand (Bonn: Bundeszentrale für politische Bildung, 2018): 153-66.

18 See Jill Lepore, "How to Steal an Election: The Crazy History of Nominating Conventions" The New Yorker (27 Jun. 2016); Stan M. Haynes, President-Making in the Gilded Age: The Nominating Convention, 1876-1900 (Jefferson, NC: McFarland, 2015). 
cess suggestively known as horse trading. As "dark horses," new candidates may "throw their hats into the ring" later on as did John W. Davis at the 1924 Democratic National Convention, which chose him on the $103^{\text {rd }}$ ballot. The most recent contested conventions took place in 1952: Both the Republican and the Democratic conventions, which eventually led to the nomination of Dwight Eisenhower and Adlai Stevenson respectively, were contested. Since then, several conventions were threatened to become contested, but eventually led to the nomination of a candidate already after the first vote - the 2016 Republican convention (and possibly the upcoming 2020 Democratic convention) among them.

The introduction of the national Presidential-nominating convention as an institution has not led to a real democratization of the nomination process. The (contested) convention has instead become a cultural sign of a political event, orchestrated for delegates and TV audiences as a colorful show while the convention's meaningful agreements are negotiated behind the scenes by political power brokers. Those latter, the grey eminences of politics, remain largely invisible, while candidates give vacuous speeches, conspicuously visible on the convention stage. Representations of contested conventions depict anonymous delegates as easily manipulated puppet voters. Adorned with campaign badges and novelty hats, they fiercely wave American flags as well as signs in support of their candidates, which, as ballots progress, swiftly end up in the trash to be replaced by new signs in support of new candidates. The epitome of political orchestration instead of deliberation, "more of an infomercial than a news event" as ABC news anchor Ted Koppel complained about the (uncontested) 1996 Republican National Convention before discontinuing his commentary, ${ }^{19}$ the brokered convention is a chronotope of political fiction that presents politics as brazen manipulation.

Presidential-nominating Conventions figure prominently in political film as symbolization of crooked political processes. Already Frank Capra's 1948 State of the Union visualizes manipulation in politics through a succession of private back rooms and their closing doors at a national convention. Rich heiress and tycoon Kay Thorndyke is aware that "no woman could ever run for president" (01:03:55), and therefore tries to install her married lover, industrialist Grant Matthews, as Republican candidate. John Frankenheimer's 1962 The Manchurian Candidate focuses on Korean War

19 See James Bennet, “Nightline' Pulls the Plug on Convention Coverage” The New York Times (15 Aug. 1996). 
veteran Raymond Shaw who had been conditioned into a sleeping assassin for an international Communist conspiracy operated by his own mother, ruthless Eleanor Iselin. The film portrays a national convention as a spectacle for gullible masses during which Shaw is supposed to kill the presidential candidate, enabling his step-father Iselin, the running mate, to embrace the presidential nomination. ${ }^{20}$ The perhaps most influential example of the convention chronotope was eventually advanced by The Best Man (1964). ${ }^{21}$ Based on the eponymous Gore Vidal play, the film narrates the final days before an unspecified party's contested national convention, in which William Russell and Joe Cantwell are the most promising contenders for the presidential nomination. The convention, "a spontaneous demonstration" which is "carefully planned" (2:03), is again depicted as an exercise in electoral manipulation in which "the best man" eventually drops out of the race, disgusted with political maneuvering. ${ }^{22}$

\section{The "decision is yours and yours alone": A Democratic Convention on The West Wing}

In "2162 Votes," $T W W$ re-imagines the chronotope of the contested convention, in this case a Democratic one, contrasting it to earlier representations in an effort to show the institution's potential for democratic deliberation. ${ }^{23}$ The race between three candidates is undecided when a fourth candidate orchestrates a campaign in order to get nominated "from the floor." At the beginning of the episode, staffer Josh Lyman explains the delegates' function in a well-established fashion: Their "job [...is] to clap and wave noise-

20 In Jonathan Demme's 2004 remake, the plot is moved into the time of the first Gulf War, introducing Manchurian Global, a military-industrial complex and thinly veiled version of Haliburton. Demme's Manchurian Candidate (with Denzel Washington, Meryl Streep, and Liev Schreiber, Paramount Pictures (2004)) came out on 29 July 2004, the last day of the Democratic convention, eerily reverberating the real convention in the film's own convention sequence. Eleanor Shaw Prentiss, played by Streep, is again a ruthless mother who aspires to becoming president (interpreted as modelled on Hillary Clinton). See Dan Glaister, "Playing with Political Paranoia" The Guardian (30 Jul. 2004).

21 The Best Man, dir. Franklin J. Schaffner, with Henry Fonda and Cliff Robertson, United Artists (1964).

22 The Best Man, in contrast to the other examples, does not identify women as the ultimate threat to political practice, but still criticizes the women's movement through the shallow and power-hungry character of Sue-Ellen Gamage, the head of the party's women's division. According to William Safire, it is customary to describe the nomination process as search for "the best man" (Safire's Political Dictionary (Oxford: Oxford UP, 2008): 50).

23 “2162 Votes," dir. Alex Gaves, written John Wells, TWW, season 6 (6 Apr. 2005). 
makers for five hours straight" (9:10-9:26). But "2162 Votes" revises this convention(al) narrative when Matthew Santos, one of the original three candidates who has lost delegates to the newcomer, gives his speech: "I have been asked by people that I respect to take this opportunity to support one of the other fine candidates [...] to help decide who our nominee will be," Santos addresses the delegates. "But I can't do that [...] because it is not my place to decide who our nominee will be. That decision is yours, and yours alone" (33:49). Santos continues, fending off the idea that politicians should be assessed according to particularly rigorous moral standards: "We all live lives of imperfection and yet we cling to this fantasy that there is a perfect life and that our leaders should embody it. [...] But if we expect our leaders to live on a higher moral plane than the rest of us - aren't we just asking to be deceived?" (35:09-35:45). Here, $T W W$ offers as lesson in democratic decision-making a factor that American political fiction usually obscures: It emphasizes the role of the electorate in a political process in which politicians and voters are interdependent cogs within a complex, but not necessarily crooked machinery; a role that populist narratives eclipse with their emphasis on manipulation, but also individual agency and moral superiority of singular leaders.

Visually, "2162 Votes" mirrors its message contrasting different perspectives: Santos commands of a domineering perspective when giving his speech, looking down from the convention's stage on an anonymous mass of delegates - a sea of hats, waving signs and flags in a vast hall. But he also steps down into this hall and looks up at seemingly endless rows of seats; he takes a seat in one of these rows, overwhelmed by the hall's size and the enormous number of delegates this size implies. Establishing shots of the convention and of the speeches alternate with shots of the TV coverage of the event, which the candidates and their staff follow attentively; a visualization not only of the power of images, but also of their democratic proliferation.

While communicating a narrative about the complexity of politics that highlights the danger of the "us against them" mentality of populist political fiction, "2162 Votes" still cannot escape the emotionalism that the portrayal of a sympathetic character like Santos together with an uplifting musical score and images of delegates who are moved to tears by the candidate's speech produce. While the episode questions the traditional identification of the presidential office with a white male candidate - in place with Bartlett, subverted by Santos (the Hispanic candidate who eventually 
secures not only the nomination, but also the presidency) - it still confirms the symbolical identification particularly of the president as a flawless individual; an idea that Santos rejects in his speech but still epitomizes as a character.

\section{A "speech to end all speeches": Populist Manipulation in House of Cards}

House of Cards and Veep re-visit the chronotope of the contested convention more than a decade after $T W W$, and both shows have little interest in functioning as civics lessons as $T W W$ supposedly did. Instead, they potentiate the idea that - once the "air of impossibility is removed" - not only everyone may aspire to becoming president, but in fact everything is possible on his (rarely her) path to this political office.

Based on the successful British book and BBC miniseries of the same title, $\mathrm{HoC}$ traces the life of ruthless power-hungry Frank Underwood, joint to his wife Claire in a symbiotic goal-oriented partnership, from Democratic South Carolina Congressman and House Majority Whip to both Underwoods' vice presidencies and presidencies.

The Presidential-nominating Convention, as chronotope, epitomizes the categorical difference between candidate and incumbent. Until 1932, when Franklin D. Roosevelt gave an acceptance speech at the Democratic Presidential-nominating Convention, candidates usually did not attend the conventions at which they were nominated, advancing pleas of modesty (see Lepore), in fact avoiding unnecessary "contamination" with the sullied image of the campaigning career politician. This constellation is still pronounced in contemporary TV culture, for instance with stellar Tom Kirkman, designated survivor in the recent eponymous series, who ascends to the presidency by default after the sitting president and everyone in the presidential line of succession is killed in a terrorist attack. Kirkman, Secretary of Housing and Urban Development at the time of the attack and former university professor, is a registered Independent who never passed through a campaigning and nomination process, and this lack of political experience - while deplored at the narrative's diegetic level - is a symbolical asset, qualifying Kirkman as particularly honest and trustworthy.

$H o C$, instead, pinpoints the character of the fully corrupted, power-hungry politician through his - and her - campaigning efforts. Establishing a realistic narrative style through the show's localization in Washington, D.C. 
already in the visually impressive opening credits, the show implicates its unprincipled protagonist Underwood, his wife, and particularly Chief of Staff Doug Stamper in an increasingly improbable series of criminal acts, including murder, which the Underwoods miraculously manage to keep under the lid. In contrast to Kirkman, the fact that both Frank and Claire Underwood likewise never undergo full-fledged vetting and nomination processes emphasizes the show's central proposition that the manipulative finesse of career politicians - their main difference from Kirkman - undermines the stability of the political office.

The much-commented technique used by Frank Underwood (and, in the last season, by then-president Claire Underwood) of breaking the fourth wall and directly addressing the audience may be interpreted as a means of drawing the viewer into the know. HoC establishes a "we," an uneasy coalition between the narrative's anti-heroes and the show's audience. It advances a contradictorily elitist assumption, which is concealed underneath a populist, superficially anti-elitist political narrative that toys with conspiracy thinking. In effect, as many populist political fictions that embrace a narrative of uncovering corruption, $\mathrm{HoC}$ dismisses the average voter as uneducated and easily manipulated while addressing the (extra-diegetic) viewer as its equal.

In "Chapter 48," as Frank Underwood's first term of office draws to an end and with his own nomination seemingly secure, he proposes an open convention as purportedly democratic means to determine his running mate. ${ }^{24}$ The convention's secret goal, however, is to install Claire Underwood as vice president in an unheard-of attempt of amassing political power within the first family. Challenged, Claire leaves the convention to visit her sick mother who conveniently dies, which frees Claire to return to the convention in time and to give a "speech to end all speeches."

In contrast to " 2162 Votes," the $\mathrm{HoC}$ episode never enters the convention hall directly: As viewer, we learn about its proceedings as Underwood watches the events on TV, secluded with his Republican contender Will Conway in a small backroom. Claire Underwood's speech is short and apolitical, focusing on the empty, but longstanding conservative populist rhetoric of equaling the first family with the American nation..$^{25}$ "Loss is a

24 "Chapter 48," dir. Robin Wright, written Frank Pugliese, HoC, season 4 (4 Mar. 2016).

25 Despite of Congressman, later President Santos's appeal not to apply elevated moral standards to politicians, the character of fictional politicians can usually be assessed by their normative domestic cir- 
sobering phenomenon," she pronounces. "Several months ago, I almost lost my husband [who was shot]. Our nation almost lost a president. Loss makes us reevaluate what we hold dear. [...] I trust Francis Underwood with my life, with our nation, with our future. I hope you will, too," she ends. She thus secures for herself the vice presidency that, in turn, allows her to succeed to the presidency after her, by then already disgraced, husband's death in the show's last season. ${ }^{26}$

\section{"Start twisting some arms": Lessons in Horse Trading on Veep}

Veep, marketed as presidential comedy, was created by British director Armando Iannucci, who is also the creator of the political HBO series The Thick of It (2005-2019) and the director of the political comedy In the Loop (2009). Veep - also by means of what Brett Mills calls a "comedy verité"style $^{27}$ - presents a realist, if satirical and often cynical, picture of (vice) presidential politics. The depiction of the female vice president and later president Selina Meyer resembles that of Claire Underwood, even if the Underwoods' outstanding manipulating skills are matched only by Meyer's continuing ineptitude to conceal her numerous political blunders.

Meyer, a Maryland Senator and probably a Democrat, ${ }^{28}$ decides to run

cumstances. Husbands in happy marriages with several children make good presidents (Bartlett, Santos, Kirkman), while childless presidents like Underwood are highly suspicious. Claire Underwood, suddenly pregnant in the last season, uses her motherhood for political purposes. Selina Meyer in Veep is an incapable mother of her adult daughter, whom she misuses as a campaign prop. When she - as unmarried female vice president - becomes pregnant again in the show's first season, this causes a "credibility problem." In the presidential dramady Graves, the aging former Republican president Richard Graves (Nick Nolte) tries to make amends for his numerous political and private blunders, which also led to a fully dysfunctional family. Graves, in contrast to female presidential characters, however remains a nice guy whose ambivalent ambitions might have been fueled in the past by his younger wife, who significantly embarks on a political career of her own within the diegetic space of the series.

26 After accusations of sexual harassment, Kevin Spacey was removed from $\mathrm{HoC}$ after the fifth season. On the final sixth season, Claire Underwood returns as president who succeeded her husband after he was impeached and then died. As president, it is argued, Claire Underwood "weaponizes" feminism, by appointing an all-female cabinet whose members she manipulates. She is not a feminist role-model, as Conor Friedersdorf makes clear in "Feminism, Depravity, and Power in House of Cards" (The Atlantic, 20 Feb. 2014), but it seems doubtful, too, whether her character should be praised for broadening the repertoire of female characters, given the fact that the character of the particularly threatening, power-hungry female string-pulling political manipulator already occupies a firm - and by no means feminist - place within the US-American political imaginary.

27 Brett Mills, “Comedy Verité: Contemporary Sitcom Form” Screen 45.1 (2004): 63-78.

28 Party affiliations are never made explicit on Veep, but the argument has been made that Meyer is a Demo- 
for president in a 2012 election, but loses against her party opponent Stuart Hughes in the primaries, whose vice president she later becomes. Hughes resigns during the next round of primaries four years later, letting Meyer move up to the presidency. In contrast to Kirkman, Meyer's entry into the White House via, so to speak, the back door of the vice presidency does not qualify her as particularly trustworthy candidate. To the contrary, the fact that she does not win a general election, like Claire Underwood or Mackenzie Allen in the series Commander in Chief, rather seems to illustrate that realist political fiction does not believe in female presidents. ${ }^{29}$ Meyer does not win the next election, either, yet returns to the political circus four years later, then running for president again.

The seventh and final season of Veep ends with "Veep," an episode that focuses on a contested convention and the selection of Meyer's running mate ${ }^{30}$ Like in $\mathrm{HoC}$, the brokered convention in Veep is depicted almost exclusively from the nominees' and their staffers' perspectives and through fictional TV coverage. The delegates' role is, once again, ornamental. At the end of the second day, the convention is still deadlocked between Governor Leslie Calhoun, a born-again Christian, Representative Jonah Ryan who believes that "Arab math" threatens Western culture, Senator Kemi Talbot, and Selina Meyer who is in the lead by 100 votes. At a late-night meeting, the convention's chairman points out that, with the first ballot over, no candidates are bound any more. "So, it's time to get out there and start twisting some arms and pinching nipples. And what else?," he asks his staffer, who answers: "And may the best man win," quoting the traditional slogan despite the fact that two of the candidates, and the two most promising ones, are women.

After Meyer accidentally breaks the recently introduced North Carolina bathroom bill, which earns her support from the LGBTQI community, she seems to be on the path of winning the nomination. But the race is not over

crat not only because of political topics raised by her, but also because of a Presidential elections result map that marks in blue the states/districts won by Meyer ("Election Night," season 4).

29 Positively portrayed Mackenzie Allen, presented as first female president in the ABC-series Commander in Chief (2005-2006, created Rod Lurie), ascends from her office as vice president after the sitting president has died. She becomes commander in chief, the series implies, only by sidestepping the usual selection process. The only exception to the rule that female candidates cannot win elections in US-American TV culture is the character of Elizabeth McCord of Madame Secretary, who is elected US president, but only after she has proven her abundant skills by surviving five seasons as Secretary of State. Madame Secretary, created by Barbara Hull, with Téa Leoni and Tim Daly, CBS (2014-2019).

30 “Veep," dir. David Mandel, written David Mandel and Armando Iannucci, Veep, season 7 (12 May 2019). 
yet: Ryan is suddenly on the tear after an Islamist terrorist turns out to also be a math teacher. Eventually, Meyer wins the nomination and becomes president by making the completely inept Ryan her vice president, by trading away same-sex marriage to Talbot, and by framing and sending to prison her personal aide Gary Walsh, the most loyal character on the show.

Veep, in its final round, gathers pace, sharpening Meyer's character traits from ineptitude to unscrupulousness. With her slogan "New. Meyer. Now," her show(wo)manship more and more resembles contemporary real-life substance-free presidential grandstanding. Incredibility in this political fiction might thus be trumped by political reality, rendering the pointed emphasis of realist fiction from $\mathrm{HoC}$ to Veep on drama and satire less astonishing. Foremost, these shows together with other political series from Designated Survivor to Graves indicate, not surprisingly, that the longstanding trope of distrust in politicians and politics remains in place, no longer excluding the character of the president (with the exception of Kirkman who is an academic, an Independent, and most importantly not a career politician). ${ }^{31}$ And while political film, according to a survey conducted by sociologists around William D. McIntosh ${ }^{32}$, used to favor liberal politicians, this preference is apparently no longer in place in contemporary TV culture.

The mistrust in female politicians, at the same time, has become particularly pronounced. The 2012 TV production Game Change targeted Sarah Palin as a concrete political figure. ${ }^{33}$ Emanuelle Wessels argues that Meyer's "professional failings, personal foibles and conventionally feminine attractiveness" link her to Palin or Michele Bachman..$^{34}$ Margaret Tally, in contrast, perceives the character as yet another fictionalized portrait of Hillary Clinton. ${ }^{35}$ But increasingly, fictional representations of "Hillary Clinton" have come to symbolize a woman who is part of a sinister elite and who

31 Gregory Frame makes a similar argument in "The Leader of the Free World? Representing the Declining Presidency in Television Drama," Politics and Politicians in Contemporary US Television: Washington as Fiction, ed. Betty Kaklamanidou and Margaret J. Tally (London: Routledge, 2017), e-book.

32 William D. McIntosh, Rebecca M. Murray, John D. Murray, and Debra Sabia, "Are the Liberals Good in Hollywood? Characteristics of Political Figures in Popular Films from 1945 to 1998" Communications Report 16.1 (2003): 57-67.

33 Game Change, dir. Jay Roach, with Julianne Moore, Woody Harrelson, and Ed Harris, HBO (2012).

34 Emanuelle Wessels, "HBO's Veep, Postfeminism, and Political Humor" Mediacommons (23 Aug. 2012).

35 Margaret J. Tally, "'Call it the Hillary effect': Charting the Imaginary of 'Hillary Narratives," Politics and Politicians in Contemporary US Television: Washington as Fiction, ed. Betty Kaklamanidou and Margaret J. Tally (London: Routledge, 2017), e-book. The USA Network-series Political Animals (created Greg Berlanti, with Sigourney Weaver and Ciarán Hinds, 2012) presents one of the very few positive reflections of a female presidential candidate purportedly based on Hillary Clinton. 
cannot be trusted. Most shows, in fact, leave the actual political agenda, and the person, of its female characters unspecified, while arguing that men are the better candidates.

Alisa Valdes-Rodriguez posits that "political movements of a sweeping scope must be rooted in prior cultural movements, in order to prime the public for change." ${ }^{36}$ If, as Elizabeth Haas, Terry Christensen, and Peter J. Haas contend, political fiction "debate[s] the great issues of the day as the nation debate[s] them, sometimes ahead and sometimes lagging behind, sometimes dissenting and sometimes reinforcing" $(278)^{37}$, it is significant that contemporary TV culture remains extremely reluctant to picture women as elected presidents. ${ }^{38}$

\section{Conclusion}

Political fiction, Dorothea Will argues, "is an important vehicle for pointing out flaws in our political systems, for making politics more easily approachable, for creating a more critical audience, for attacking political orders and norms, and for consoling us" (139). ${ }^{39}$ Realist presidential drama(dy) fulfills some of these functions. It also informs us of the shortcomings of a contemporary political imagination that still seems to be at odds with the idea of a female president. The air of impossibility, it seems, is far from being removed where women are concerned who run for president.

Due to its focus on the presidential character, presidential drama(dy) as

36 Alisa Valdes-Rodriguez, "The AP and CNN Get 'The Huxtable Effect' All Wrong" AlterNet (13 Nov. 2008).

37 Elizabeth Haas, Terry Christensen, and Peter J. Haas, Projecting Politics: Political Messages in American Film, $2^{\text {nd }}$ ed. (London: Routledge, 2015).

38 In this context, Lilly J. Goren emphasizes the fact that female presidents are generally not elected in American political fiction, to which I have pointed above, giving as only exception Allison Taylor (Cherry Jones) a Republican president in season 7 and 8 on 24, who takes office in 24: Redemption, the film dir. by Jon Cassar, with Kiefer Sutherland, Fox (2008). See Lilly J. Goren, "Fact or Fiction: The Reality of Race and Gender in Reaching the White House," Women and the White House: Gender, Popular Culture, and Presidential Politics, ed. Justin S. Vaughn and Lilly J. Goren (Lexington: U P of Kentucky, 2013): 97-120. The romantic comedy Kisses for My President (dir. Curtis Bernhard, with Polly Bergen and Fred MacMurray, Warner Bros. Pictures, 1964) may be an earlier example, but this film's female president does not last long in the White House.

39 Dorothea Will, "The Humane Face of Politics? Political Representations, Power Structures, and Gender Limitations in HBO's Political Comedy Veep," Transgressive Television: Politics and Crime in $21^{\text {st }}$-Century American TV Series, ed. Birgit Däwes, Alexandra Ganser, and Nicole Poppenhagen (Heidelberg: Winter, 2015): 127-44. 
a form is also slow to (re-)imagine the role of the electorate. While $T W W$ attempts a reconfiguration of the voter into an active political force, Veep and $\mathrm{HoC}$ address their audiences at an extra-diegetic level (letting them into the know), yet disregard the electorate at the level of the story. The narrative of mainly equating politics with corruption, self-service and sometimes ineptitude, while critical and progressive on the surface, runs the risk of perpetuating an undifferentiated narrative of ubiquitous political manipulation that is wide open to cooptation by conspiracy thinking. 